\title{
An efficient solvent-free synthesis of 3-methyl-4-nitro-5-styrylisoxazoles using solid nano-titania
}

\author{
KARTIKEY DHAR DWIVEDI ${ }^{\mathrm{a}}$, SAMEER REDDY MARRI ${ }^{\mathrm{b}}$, SATISH KUMAR NANDIGAMA $^{\mathrm{c}}$ \\ and RAJU L CHOWHAN ${ }^{a, *}$ \\ ${ }^{a}$ Centre for Applied Chemistry, Central University of Gujarat, Gandhinagar, Gujarat 382 030, India \\ ${ }^{\mathrm{b}}$ School of Chemical Sciences, Central University of Gujarat, Gandhinagar, Gujarat 382 030, India \\ ${ }^{\mathrm{c} N a n o s c i e n c e ~ a n d ~ N a n o t e c h n o l o g y ~ L a b o r a t o r y, ~ D e p a r t m e n t ~ o f ~ C h e m i s t r y, ~ G i t a m ~ I n s t i t u t e ~ o f ~ S c i e n c e, ~ G I T A M, ~}$ \\ Visakhapatnam, Andhra Pradesh 530 045, India \\ E-mail: rchowhan@cug.ac.in
}

MS received 10 July 2018; revised 6 August 2018; accepted 7 August 2018; published online 6 September 2018

\begin{abstract}
An efficient and solvent-free procedure for the synthesis of 3-methyl-4-nitro-5-styrylisoxazoles using nano-titania as solid support and recyclable catalyst is presented. This method provides clean, simple, solvent-free and useful alternative to synthesize styrylisoxazoles. The use of nano-titania provides excellent yield, leading to an easy separation and reuse of the catalyst up to four times without loss of yield. Also, the green matrices calculation shows low environment impact. The green chemistry matrices atom economy, reaction mass efficiency (RME), process mass intensity and E-factor are also calculated which show that this methodology is green and eco-friendly. The catalytic efficiency of heterogeneous $\mathrm{TiO}_{2} \mathrm{NPs}_{\text {sas successfully }}$ demonstrated by recyclability experiment (up to 4 cycles). The sustainability of the catalyst was tested by performing recyclability experiment up to 4 cycles. Calculated turn over frequency (TOF) for each cycle indicates the protocol as sustainable.
\end{abstract}

Keywords. Styrylisoxazoles; nano-titania $\left(\mathrm{TiO}_{2} \mathrm{NPs}\right)$; solvent-free synthesis, green methodology; nanocatalyst.

\section{Introduction}

Green chemistry has become an important area of research in the field of chemistry. Designing of a catalyst which is easy to separate, reusable, inexpensive and heterogeneous in nature is an important area of research in green chemistry. ${ }^{1}$ Along with it, organic reactions in solvent-free condition are current topics of interest in green chemistry.

For the formation of catalysts, nanoparticles have proved to be useful due to their high level of catalytic activities and their structural features. ${ }^{2}$ After decades of research, nano $\mathrm{TiO}_{2}$ was found to have multiple potential application in catalytic reactions such as esterification, ${ }^{3}$ for proton membrane cell, ${ }^{4}$ degradation of methyl parathion, ${ }^{5}$ photodecomposition of methyleneblue by highly dispersed $\mathrm{Ag}^{6}$ and synthetic reactions such as synthesis of dibenzo [a,j] xanthenes, ${ }^{7}$ cross linking of cotton cellulose with succinic acid under UV. ${ }^{8}$ Reports also inferred that the catalytic properties of $\mathrm{TiO}_{2}$ nano particles were improved by functionalising with sulfonic acid by reacting it with chlorosulfonic acid which was used as a catalyst for the synthesis of pyrimidines, benzothioles and chalcones under solvent-free conditions. $^{9}$

Compounds containing isoxazole (Figure 1) framework are known to inhibit targets COX-1 inhibitor, NSAID, COX-2 inhibitor (Valdecoxib), 5-lipoxygenase and cyclooxygenase inhibitors, ${ }^{10}$ and additionally they possess diverse biological activities such as antimicrobial, anti-inflammatory, analgesic, ${ }^{11}$ antifungal, ${ }^{12}$ and antiviral. Due to high potential of the isoxazole derivatives in drug discovery, there is a growing interest to design a clean and rapid method for their synthesis.

\footnotetext{
*For correspondence

Electronic supplementary material: The online version of this article (https://doi.org/10.1007/s12039-018-1534-0) contains supplementary material, which is available to authorized users.
} 


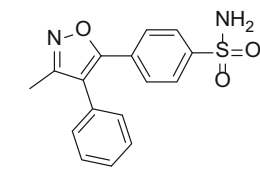

Valdecoxib NSAID, COX-2 inhibitor
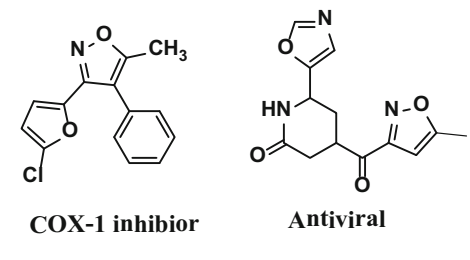

Figure 1. Some examples of biologically active isoxazole derivatives.

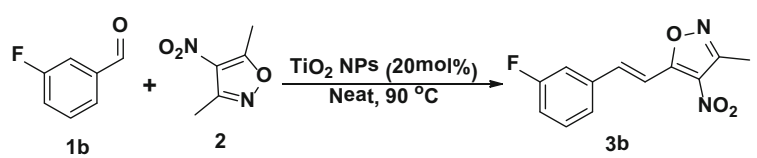

Scheme 1. Recyclability experiment of $\mathrm{TiO}_{2}$ nano particle.

Various catalytic methods have been developed for the synthesis of styrylisoxazoles in different conditions like in piperidine, ${ }^{13}$ ionic liquids, ${ }^{14}$ sodium hydroxide, ${ }^{15}$ and pyrrolidine. Dehydration reaction performed in different catalytic media in different conditions like in sulphuric acid, ${ }^{16}$ sulphuric acid in glacial acetic acid, ${ }^{17}$ Cobalt(III)(salpr)(OH) under neutral condition, ${ }^{16} \mathrm{P}_{2} \mathrm{O}_{5}$ under grinding condition, ${ }^{18}$ copper(II) chloride in ethanol and microwaves, ${ }^{19}$ and Preyssler and WellsDawson hetero-polyacids in bulk and supported on silica. ${ }^{20,21}$

Herein we report our findings using nano-titania as a cheap, stable, reusable and easily recoverable catalyst for a simple, clean, environmentally friendly and solvent-free method for synthesis of 3-methyl4-nitro-5-styrylisoxazoles (Scheme 1). Products were isolated quantitatively in analytically pure form without performing column chromatography. The recyclability experiment has shown good results with negligible reduction in yield after four cycles. Green chemistry matrices (Atom Economy, Reaction Mass Efficiency (RME), E-factor, and Process Mass Intensity) were calculated under optimized conditions which indicated that the developed protocol is in good agreement with green and sustainable parameters.

\section{Experimental}

To the mixture of aldehyde $1 \mathrm{a}(1 \mathrm{mmol})$ and 3,5-dimethyl-4nitroisoxazole $2(1 \mathrm{mmol})$ the $\mathrm{TiO}_{2} \mathrm{NPs}(20 \mathrm{~mol} \%)$ added and stirred for the $90 \mathrm{~min}$ at $90^{\circ} \mathrm{C}$. Reaction progresses was determined by thin layer chromatography (TLC). After completion of the reaction was cooled to room temperature, the residue was dissolved in dichloromethane and filtered. The organic layer was concentrated under reduced pressure to give residue, recrystallized in methanol to give analytically pure product 3a as yellow solid. $\mathrm{R}_{f}=0.30$ (Hexane); M.p. $120-122^{\circ} \mathrm{C}$; ${ }^{1} \mathrm{H}$ NMR $(500 \mathrm{MHz}, \mathrm{CDCl} 3) \delta 7.80(\mathrm{~d}, J=16.5 \mathrm{~Hz}, 1 \mathrm{H})$, $7.68(\mathrm{~d}, J=16.4 \mathrm{~Hz}, 3 \mathrm{H}), 7.46(\mathrm{~s}, 2 \mathrm{H}), 7.26(\mathrm{~s}, 1 \mathrm{H}), 2.61$ (s, 3H).

\section{Results and Discussion}

$\mathrm{TiO}_{2}$ NPs catalyst was synthesized and characterized as described in literature. ${ }^{22}$ Formation of the $\mathrm{TiO}_{2}$ NPs was confirmed by the analytical data (Figure 2). The sharp peak powder XRD (Figure 2a) pattern shows the crystalline nature of the synthesized catalyst. Peaks at (101), (004), (200), (105), (211), (204), (116), (220) and (215) correspond to anatase phase of $\mathrm{TiO}_{2}$ NPs and compared with standard (JCPDS card no. 21-1272). DLS analysis of the sample has shown the size of $\mathrm{TiO}_{2}$ NPs was within narrow range of 30-60 nm (Figure 2d).

SEM images indicate the uniform size and spherical shape of the particles (Figure 2b). TEM image (Figure 2c) at $200 \mathrm{~nm}$ scale spherical shape of the particles uniform size. The EDS (energy dispersive $\mathrm{X}$-ray spectroscopy) spectrum of synthesized $\mathrm{TiO}_{2} \mathrm{NPs}$ confirms the presence of $\mathrm{Ti}$ and $\mathrm{O}$ (Figure 2f). The FTIR (Figure 2e) analysis shows peaks at $3390 \mathrm{~cm}^{-1}$ in the spectra is due to the stretching vibration of the -OH group. In the spectrum of pure $\mathrm{TiO}_{2}$, the peaks at $512 \mathrm{~cm}^{-1}$ show stretching vibration of Ti-O and peaks at $812 \mathrm{~cm}^{-1}$ as stretching vibrations of Ti-O-Ti.

To optimize the conditions, the one-pot reaction of aldehyde 1a (1 $\mathrm{mmol})$ and 3,5-dimethyl-4nitroisoxazole $2(1 \mathrm{mmol})$ in the presence of nanocrystaline $\mathrm{TiO}_{2} \mathrm{NPs}$ as solid support was carried out under different conditions (Table 1). Examining different solvents confirms that solvent-free condition is the best choice (Entries 1-9). Investigation of the temperature effect, corroborated that $90^{\circ} \mathrm{C}$ is the best (Entries 9 15). The catalyst amount has been also examined to obtain the satisfactory results and optimum $20 \mathrm{~mol} \%$ of $\mathrm{TiO}_{2}$ gave best results (Table 1, Entries 12-14). It was also observed that further increasing the temperature did not increase the yield of the reaction. (Entries 12 and 15).

On the basis of optimized condition (Table 1) the reaction of various aldehydes $\mathbf{1}$ with nitroisoxazole $\mathbf{2}$ have been conducted by $\mathrm{TiO}_{2}(20 \mathrm{~mol} \%)$ under solvent free condition at $90^{\circ} \mathrm{C}$ to obtain 3-methyl-4-nitro-5styrylisoxazoles (Table 2). In case of the solid aldehyde the solvent was added 1-2 drop and reaction performed in same manner. It could be seen different aldehydes with electron-withdrawing and electron-donating substituents at the $\mathrm{C} 2, \mathrm{C} 3$ and $\mathrm{C} 4$ position of the aldehydes underwent the condensation reaction successfully 
(a)

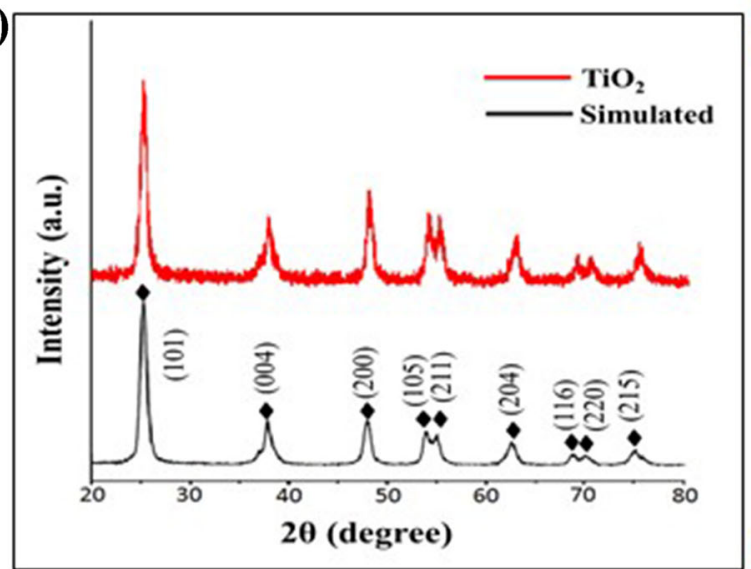

(c)

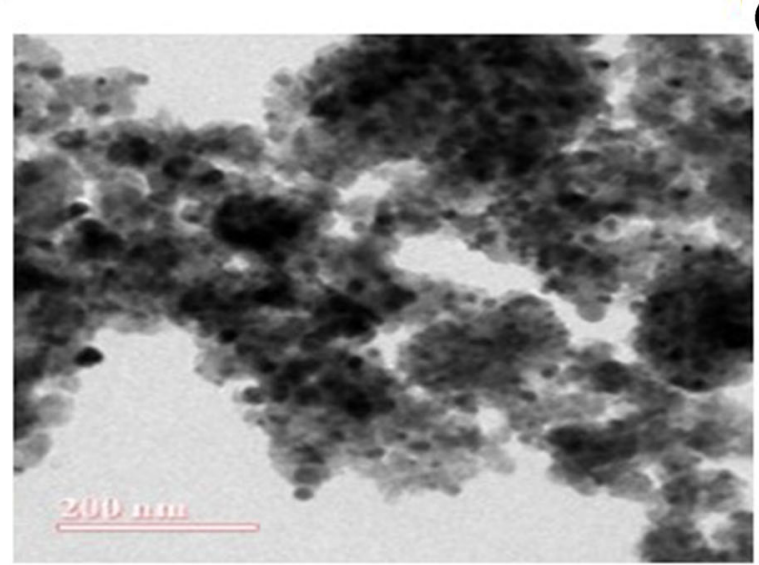

(e)

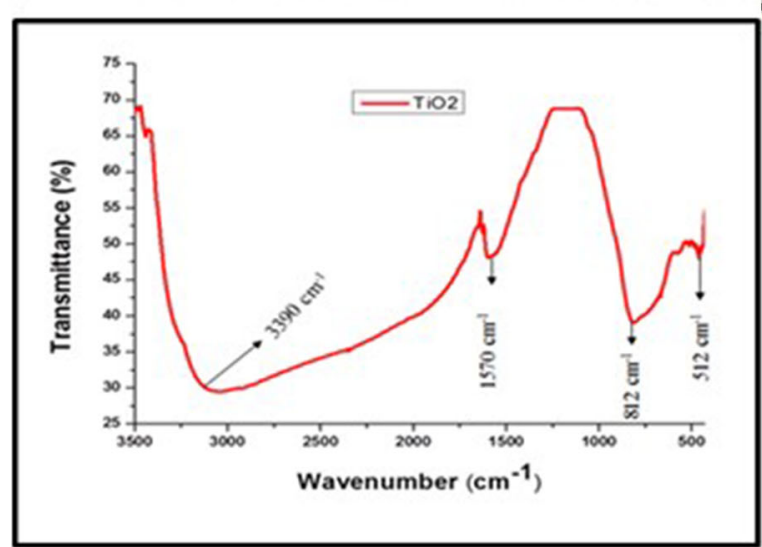

(b)

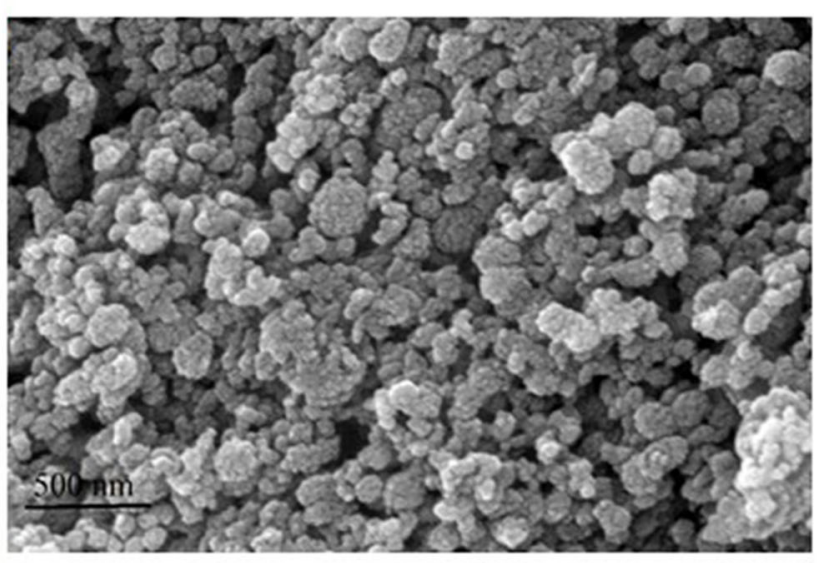

(d)

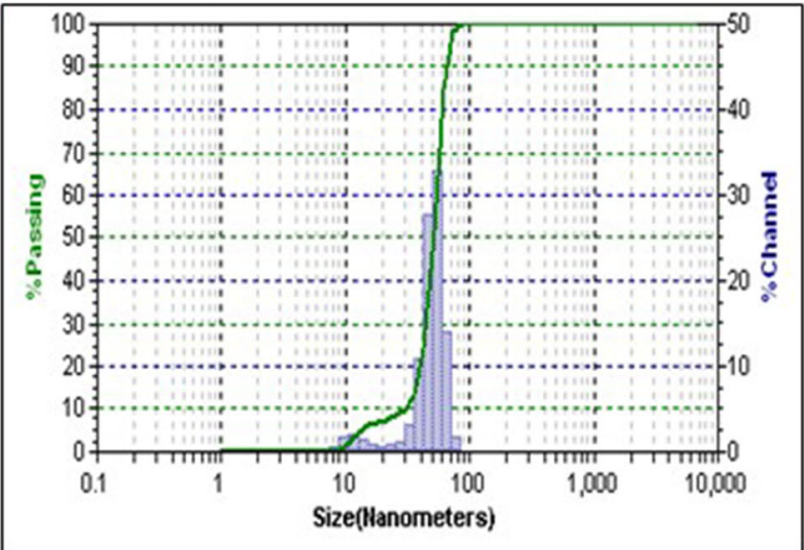

(f)

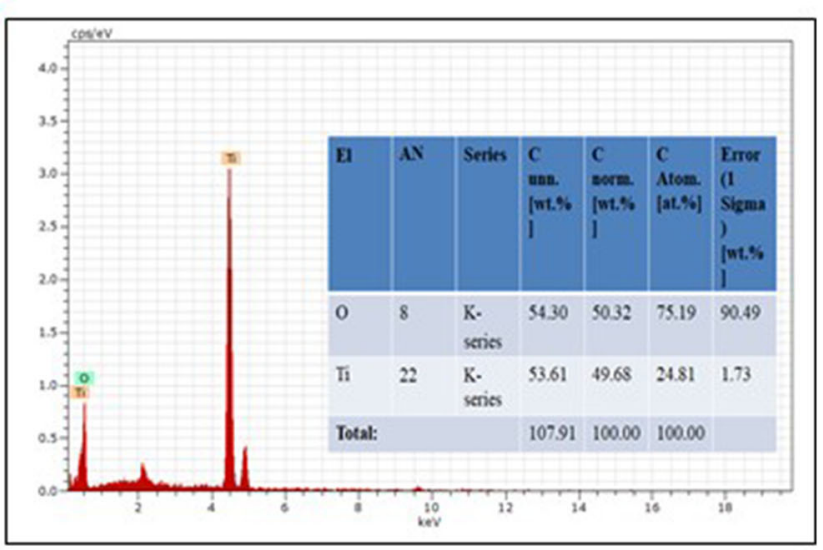

Figure 2. Characterization of $\mathrm{TiO}_{2} \mathrm{NP}$ catalyst. (2a) Powder XRD with the simulated graph (JCPDS Card no. 21-1272). (2b) FESEM image at $200 \mathrm{~nm}$ scale. (2c) TEM image at $200 \mathrm{~nm}$ scale. (2d) DLS analysis plot showing the distribution of particle size narrow range with avg. size of $38 \pm 5 \mathrm{~nm}$. (2e) FTIR spectra from 500 to $4000 \mathrm{~cm}^{-1}$. (2f) EDX elemental analysis.

(Table 2, Entries 3a-3p) The methoxy substituents at $\mathrm{C} 4$ position (Table 2, Entry $3 \mathrm{~h}$ ) lower the yield to $80 \%$ but in presence of strong electron withdrawing group at $\mathrm{C} 3$ and $\mathrm{C} 4$ position (Table 2, Entries 3b, 3c) afforded the desired product in $86 \%$ and $85 \%$ yield respectively.

The recyclability and sustainability of the catalyst $\mathrm{TiO}_{2}$ was examined (Figure 3 ) and performed up to four cycles using $\mathbf{1 b}$ and $\mathbf{2}$ (Scheme 1) (for experimental see supplementary information). It was observed that the efficiency of the catalyst was found to be retained even after four consecutive cycles with negligible loss in catalytic property.

Turn over frequency was calculated for each cycle (Figure 3) of the reaction (3b). For freshly prepared catalyst $9.10 \times 10^{-4} \mathrm{~s}^{-1}$ and for 4 th run it was found 
Table 1. Optimization of the one-pot condensation reaction. ${ }^{\mathrm{a}}$

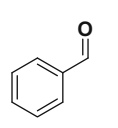

1a

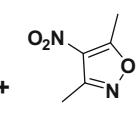

$\mathrm{TiO}_{2} \mathrm{NPs}(20 \mathrm{~mol} \%)$ Condition

\begin{tabular}{llllll}
\hline Entry & Solvent & $\mathrm{T}^{\circ} \mathrm{C}$ & $\begin{array}{l}\text { Catalyst } \\
(\text { wt. \% })\end{array}$ & $\begin{array}{l}\text { Time } \\
(\mathrm{min})\end{array}$ & $\begin{array}{r}\text { Yield } \\
(\%)^{b}\end{array}$
\end{tabular}

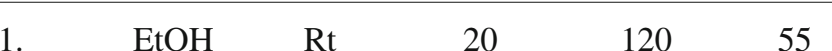

Reflux

3. DCM Rt 20

4. DCM Reflux 20

5. $\mathrm{MeOH}$ Rt 20

6. MeOH Reflux 20

7. Water Rt 20

8. Water Reflux 20

$\begin{array}{lllll}9 . & - & \text { Rt } & 20\end{array}$

10. $\quad-\quad 50^{\circ} \mathrm{C} \quad 20$

$11 . \quad-\quad 80^{\circ} \mathrm{C} \quad 20$

12. $\quad-\quad 90^{\circ} \mathrm{C} \quad 20$

$13 . \quad-\quad 90^{\circ} \mathrm{C}-25$

14. $\quad-\quad 90^{\circ} \mathrm{C} \quad 10$

15. $\quad-\quad 110^{\circ} \mathrm{C} \quad 20$

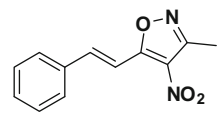

$90 \quad 68$

$130 \quad 40$

$100 \quad 52$

$135 \quad 50$

95
135

$150 \quad 50$

$110 \quad 65$

$135 \quad 50$

$120 \quad 75$

$100 \quad 81$

$\mathbf{7 8} \quad 86$

$85 \quad 86$

$90 \quad 75$

$100 \quad 86$

${ }^{a}$ Reaction conditions; aldehyde $(1 \mathrm{mmol}), 3,5$-dimethyl-4nitroisoxazole $(1 \mathrm{mmol})$ and solvent $(2 \mathrm{~mL}) .{ }^{\mathrm{b}}$ Isolated yield.

$8.65 \times 10^{-4} \mathrm{~s}^{-1}$ observations clearly show there is very slight change in the frequency. These observations clearly indicate that there is very small loss in the catalytic efficiency of the catalyst at the end of $4^{\text {th }}$ cycle.

Green chemistry matrices calculations ${ }^{23}$ like atom economy reaction catalysts for mass efficiency should be high, and environmental factor, as well as process mass intensity, should be low for a standard green chemistry reaction. ${ }^{24}$ Green chemistry matrixes were calculated for reaction involving substrates $\mathbf{1 b}$ and $\mathbf{2}$ to give $\mathbf{3 b}$ as model optimized reaction, and found high atom economy $($ A.E. $=93.23 \%)$, reaction mass efficiency $($ R.M.E. $=91.36 \%)$, small E-factor $($ E-factor $=$ 0.0945 ) and process mass intensity (P.M.I. factor $=$ 1.094). (Detailed calculations for all the reactions are included in supplementary information). These values clearly indicate the efficacy of the present protocol.

The mechanism of product formation was reasoned as follows. The $\mathrm{TiO}_{2}$ nano particles provide solid support facilitate activation of the 3,5-dimethyl-4-nitroisoxazole known to undergo keto-enol tautomerism type (I) ${ }^{24}$ The $\mathrm{TiO}_{2}$ catalyst activated the aldehyde which gives the intermediate aldol adduct (II) and due to heating condition dehydration occurs giving the 3-methyl-4nitro-5-styrylisoxazoles (III), (Figure 4).
Table 2. Substrate scope for synthesis of 3-methyl-4-nitro5 -styrylisoxazoles ${ }^{\mathrm{a}, \mathrm{b}}$.
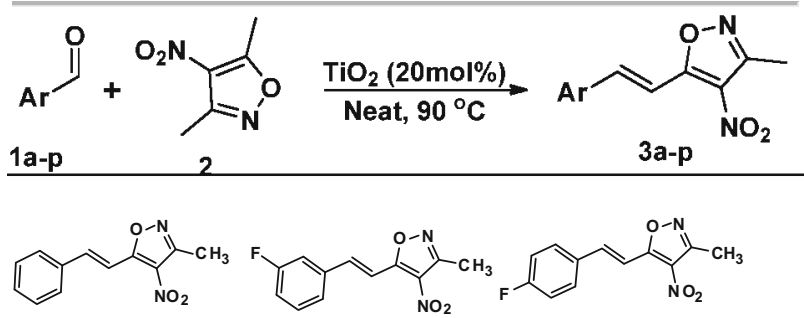

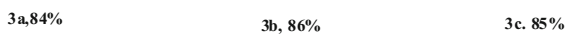
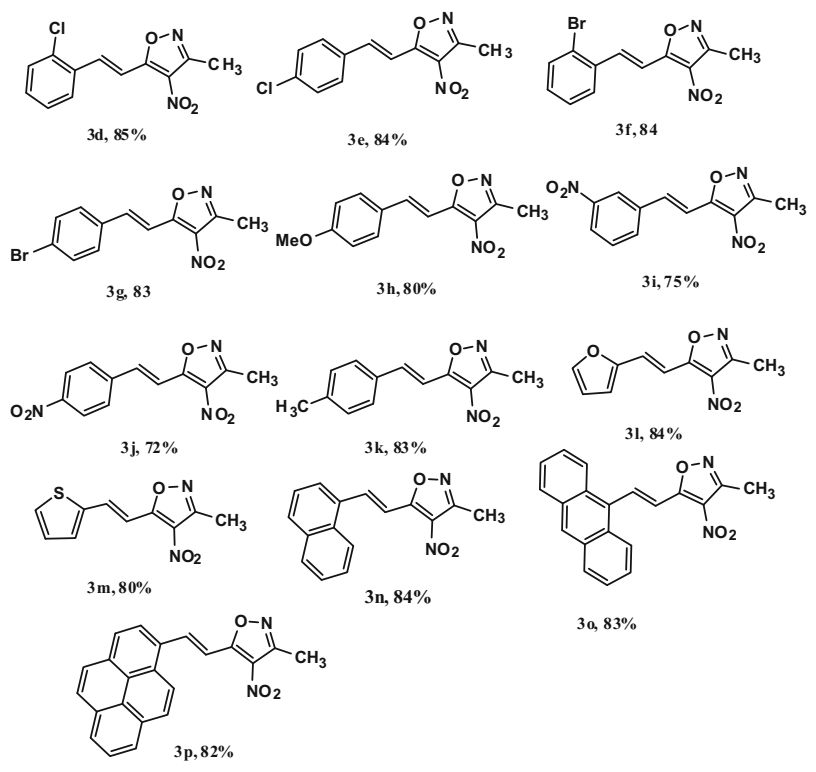

${ }^{a}$ Reaction conditions: unless otherwise specified, the reaction was carried out with aldehydes $(\mathbf{1 a - p})(1.0 \mathrm{mmol}), 3,5-$ dimethyl-4-nitroisoxazole (2) $(1.0 \mathrm{mmol})$ and $\mathrm{TiO}_{2}$ NPs $(20$ mol\%) under neat condition. ${ }^{b}$ Isolated yields of the product $(\mathbf{3 a}-\mathbf{p})$.

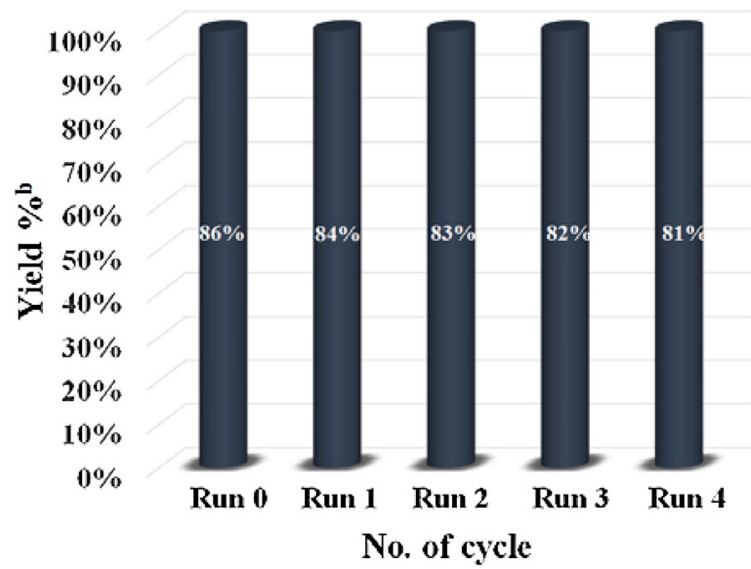

Figure 3. Recyclability experiment of $\mathrm{TiO}_{2}$ nano particle. ${ }^{\mathrm{b}}$ Isolated yield. 


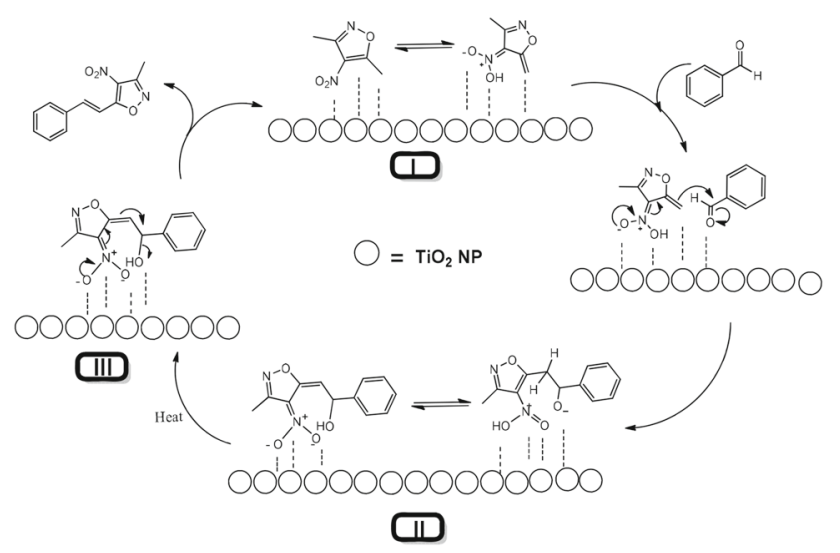

Figure 4. Plausible mechanism for the synthesis of 3-methyl-4-nitro-5-styrylisoxazoles using nano titania.

\section{Conclusions}

In conclusion, we have successfully synthesized 3-methyl-4-nitro-5-styrylisoxazoles in solvent-free $\mathrm{TiO}_{2}$ NPs-catalyzed at $90^{\circ} \mathrm{C}$ for the first time. This newly developed method offers several advantages including mild reaction condition, high yield, and reusable catalyst. In addition, turn over frequency calculations for recyclability experiment have shown good results indicating negligible loss in catalytic activity of the $\mathrm{TiO}_{2}$ NPs. Greenness and sustainability of the protocol were established by green chemistry matrices calculations for the reaction which gave high atom economy and reaction mass efficiency values, and low E-factor.

\section{Supplementary Information (SI)}

Characterization data and spectra for all the compounds are provided in the Supplementary Information which is available at www.ias.ac.in/chemsci.

\section{Acknowledgements}

M. S. R and K.D.D thank UGC for Non-NET fellowship and the Central University of Gujarat for infrastructure to carry out the work. K.D.D would like to thank Dr. P.C. Jha, Chairperson, CAC, CUG for encouragement and support. Authors also thank MRC, MNIT, Jaipur for analytical support.

\section{References}

1. Gawande M B, Branco P S and Varma R S 2013 Nanomagnetite $\left(\mathrm{Fe}_{3} \mathrm{O}_{4}\right)$ as a support for recyclable catalysts in the development of sustainable methodologies Chem. Soc. Rev. 423371

2. Koukabi N, Kolvari E, Zolfigol M A, Khazaei A, Shaghasemi B S and Fasahati B 2012 A magnetic particle-supported sulfonic acid catalyst: Tuning catalytic activity between homogeneous and heterogeneous catalysis Adv. Synth. Catal. 3542001
3. Zhang W F, He Y L, Zhan M S, Yin Z and Chen Q 2000 Raman scattering study on anatase $\mathrm{TiO}_{2}$ nanocrystals $J$. Phys. D Appl. Phys. 33912

4. Rajalakshmi N, Lakshmi N and Dhathathreyan K S 2008 Nano titanium oxide catalyst support for proton exchange membrane fuel cells. Int. J. Hydrog. Energy 337521

5. Wang J, Sun W, Zhang Z, Zhang X, Li R, Ma T, Zhang $\mathrm{P}$ and Li Y 2007 Sonocatalytic degradation of methyl parathion in the presence of micron-sized and nanosized rutile titanium dioxide catalysts and comparison of their sonocatalytic abilities J. Mol. Catal. A: Chem. 27284

6. Lin $\mathrm{C} \mathrm{H}$, Lin $\mathrm{Y} \mathrm{C}$, Chang $\mathrm{C} \mathrm{L}$, Chen W C, Cheng S Y, Wang Y H, Lin S C and Lee S H 2007 Photodecomposition of methylene-blue by highly-dispersed nano $\mathrm{TiO}_{2} / \mathrm{Ag}$ catalyst React. Kinet. Catal. Lett. 90 267

7. Mirjalili B, Bamoniri A, Akbari A and Taghavinia A 2011 Nano- $\mathrm{TiO}_{2}$ : An eco-friendly and re-usable catalyst for the synthesis of 14-aryl or alkyl-14H-dibenzo [a, j] xanthenes J. Iran. Chem. Soc. 8 S129

8. Chen C C and Wang C C 2006 Crosslinking of cotton cellulose with succinic acid in the presence of titanium dioxide nano-catalyst under UV irradiation J. Sol-Gel Sci. Technol. 4031

9. Rahmani S, Amoozadeh A and Kolvari E 2014 Nano titania-supported sulfonic acid: An efficient and reusable catalyst for a range of organic reactions under solvent free conditions Catal. Commun. 56184

10. Flynn D L, Belliotti T R, Boctor A M, Connor D T, Kostlan C R, Nies D E, Ortwine D F, Schrier D J and Sircar J C 1991 Styrylpyrazoles, styrylisoxazoles, and styrylisothiazoles. Novel 5-lipoxygenase and cyclooxygenase inhibitors J. Med. Chem. 34518

11. (a) Rajanarendar E, Reddy K G, Krishna S R, Shireesha B, Reddy Y N and Rajam M V 2013 Design, synthesis, antimicrobial, anti-inflammatory, and analgesic activity of novel dihydrobenzo furo[3,2-e]isoxazolo[4,5b]azepin-5(5aH)-ones Med. Chem. Res. 22 6143; (b) Rajanarendar E, Reddy M N, Krishna S R, Murthy K R, Reddy Y N and Rajam M V 2012 Design, synthesis, antimicrobial, anti-inflammatory and analgesic activity of novel isoxazolyl pyrimido[4,5-b]quinolines and isoxazolyl chromeno[2,3-d]pyrimidin-4-ones Eur. J. Med. Chem. 55273

12. Sailaja S, Rao E T, Rajanarendar E and Krishnamurthy A 1988 Synthesis of 3-(5-methyl-3-isoxazolyl)2-styrylquinazolin-4 (3H)-ones and their antifungal activity ChemInform 1938

13. Rajanarendar E, Ramesh $\mathrm{P}$ and Karunakar D 2003 Michael additions on isoxazole derivatives under solvent-free conditions Indian J. Chem. 42B 1994

14. Rajanarendar, Raju S, Reddy A S R, Reddy K G and Reddy M N 2010 A fast and highly efficient protocol for synthesis of pyrrolo [2, 3-d] isoxazoles and a new series of novel benzyl bis-pyrrolo [2, 3-d] isoxazoles using task-specific ionic liquids as catalyst and green solvent Chem. Pharm. Bull. 58833

15. Pei Q L, Sun H W, Wu Z J, Du X L, Zhang X M and Yuan W C 2011 Catalytic asymmetric 1, 6-michael 
addition of arylthiols to 3-Methyl-4-nitro-5-alkenylisoxazoles with bifunctional catalysts J. Org. Chem. 76 7849

16. Banerji A and Goomer N C 1980 New synthesis of flavone Synthesis 11874

17. Furniss B S 1989 Vogel's Textbook of Practical Organic Chemistry (UK: Pearson Education)

18. Nishinaga A, Ando H, Maruyama $\mathrm{K}$ and Mashino $\mathrm{T}$ 1992 A new metal complex promoted system for highly selective synthesis of $4 \mathrm{H}$-chromen-4-ones (chromones) Synthesis 09839

19. Kabalka G W and Mereddy A R 2005 Microwaveassisted synthesis of functionalized flavones and chromones Tetrahedron Lett. 466315

20. Yukio H and Noboru T 1987 A facile preparation of flavones using nonaqueous cation-exchange resin Bull. Chem. Soc. Jpn. 601919

21. (a) Bennardi D O, Romanelli G P, Sathicq A G, Autino J C, Baronetti G T and Thomas H J 2011 Wells-Dawson heteropolyacid as reusable catalyst for sustainable synthesis of flavones Appl. Catal., A Gen. 404 68; (b) Akondi A M, Sowmya M, Kantam M L, Trivedi R, Chowhan L $\mathrm{R}$ and Das A 2016 An expedient microwave assisted regio and stereoselective synthesis of spiro quinoxaline pyrrolizine derivatives and their AChE inhibitory activity New J. Chem. 41873
22. (a) Goutam S P, Saxena G, Singh V, Yadav A K, Bharagava R N and Thapa K B 2018 Green synthesis of $\mathrm{TiO}_{2}$ nanoparticles using leaf extract of Jatropha curcas L. for photocatalytic degradation of tannery wastewater Chem. Eng. J. 336 386; (b) Ramana D V, Vinayak B, Dileepkumar V, Murty U S N, Chowhan L R and Chandrasekharam M 2016 Hydrophobically directed,catalystfree, multicomponent synthesis of functionalized 3,4dihydroquinazolin-2(1H)-ones RSC Adv. 621789

23. (a) Bahuguna A, Kumar S, Sharma V, Reddy K L, Bhattacharyya K, Ravikumar P C and Krishnan V 2017 Nanocomposite of $\mathrm{MoS}_{2}-\mathrm{RGO}$ as facile, heterogeneous, recyclable, and highly efficient green catalyst for one-pot synthesis of indole alkaloids ACS Sustainable Chem. Eng. 5 8551; (b) Chowhan L R, Reddy M S and Kumar N S 2017 An efficient and rapid synthesis of 3-hydroxy-3-alkyl-2-oxindoles via $\mathrm{Zn}$ mediated barbier type reaction under aqueous condition J. Chem. Sci. 129 1205; (c) Reddy M S, Chowhan L R, Kumar N S, Ramesh P and Babu S M 2018 An expedient regio and diastereoselective synthesis of novel spiropyrrolidinylindenoquinoxalines via 1,3-dipolar cycloaddition reaction Tetrahedron Lett. 591366

24. Constable D J, Curzons A D and Cunningham V L 2002 Metrics to 'green' chemistry-which are the best? Green Chem. 4521 